- Renato Cruz Swensson Filho

- Renata Pauluci Gregório

- Clóvis Tadeu Bueno da Costa

\section{Edema pulmonar em gestante no puerpério imediato}

\author{
CET-SBA, Conjunto Hospitalar de Sorocaba, Pontificia Universidade \\ Católica de São Paulo, Sorocaba, São Paulo
}

INTRLDUÇÃa

O edema pulmonar geral é uma complicação grave da gestação e do puerpério que pode resultar em morbidade e mortalidade fetal e materna. Entre os mecanismos envolvidos, pode-se citar o aumento da pressão hidrostática e da permeabilidade capilar, e a diminuição da pressão coloidosmótica.

\section{RELATI DO CASD}

Paciente de 34 anos, secundigesta em estado físico P2 (antigo ASA II), portadora de hipertensão induzida pela gestação. A pressão arterial foi controlada sem emprego de anti-hipertensivos até o dia anterior ao parto, quando houve elevação para níveis próximos de $170 / 90 \mathrm{mmHg}$. Foi submetida à cesariana em caráter eletivo após raquianestesia com bupivacaína hiperbárica (12,5 mg) associada à morfina (100 mcg). Após o nascimento, houve elevação dos níveis pressóricos para 220/120 $\mathrm{mmHg}$, além de queixa de cefaléia e dispnéia. À ausculta pulmonar, apresentou estertores difusos. Após a administração de furosemida ( $40 \mathrm{mg}$ ) e diazepam $(2,5 \mathrm{mg})$ por via venosa, a paciente apresentou diminuição do nível de consciência e queda da saturação de $\mathrm{O}_{2}(60 \%)$. Foi então entubada e mantida em ventilação controlada. Observou-se líquido róseo na cânula traqueal, enquanto a saturação de $\mathrm{O}_{2}$ era mantida entre $88-90 \%$ com $\mathrm{FiO}_{2}$ de $100 \%$ e pressão arterial em torno de $90 / 60 \mathrm{mmHg}$. A paciente permaneceu dois dias na UTI e teve alta sem sequielas.
DISCUSSÃ

As causas de edema pulmonar na gravidez incluem o uso de agentes tocolíticos, doença cardíaca pré-existente, excesso de hidratação e pré-eclâmpsia. A elevação da pós-carga, resultado do aumento da resistência vascular sistêmica, na maior parte das gestantes não-cardiopatas, é compensada com o aumento do trabalho cardíaco; porém, se o volume intravascular e a resistência periférica excederem a capacidade de compensação cardíaca, pode haver edema pulmonar.

REFERÊNCIAS

1. Zlatnik MG. Pulmonary edema: etiology and treatment. Seminars in Perinatology. 1997;21:298-306.

2. Zhang L, et al. Analysis of inductive factors, diagnosis and treatment of 21 cases with pregnancy accompanied with pulmonary edema. Chinese J Obst Gynecol. 2001;36:92-4.

3. Sciscione AC, et al. Acute pulmonary edema in pregnancy. Obst Gynecol. 2003;101:511-5.

4. Dugernier T, et al. Acute cardiogenic pulmonary edema and pregnancy: a ten-year experience. Intensive Care Med. 1988;15:31-6.

Endereço para correspondência:

Renato Cruz Swensson Filho

Rua Arlindo de Oliveira, 150

Sorocaba (SP) - CEP 18044-240

Tel. (+55 15) 322 1-5665/9778-5890

E-mail: renatoswensson@hotmail.com 